\title{
Optimal Allocation of Flows (Water) Within the Volta Basin System of Ghana
}

\author{
Owusu-Ansah, E., Dontwi, I. K., Asiedu-Addo, S. K. \& Oduro-Yeboah, J².
}

\begin{abstract}
In this paper, a hypothetical network is proposed for the Volta Basin System (V.B.S) using the optimization technique for obtaining corresponding optimal allocation of flows from runoffs in the sub-basins (source) to the sink (Akosombo reservoir). Maximum flow paths and their capacities with consumptive and non-consumptive flows were identified. We are able to determine the optimal withdrawals on these flows for either consumptive or non-consumptive use.
\end{abstract}

Keywords Network, sub-basins, sources and sinks, consumptive and nonconsumptive flows, optimal allocation.

\section{Introduction}

Water resources management problems in Ghana have received considerable attention in the last three decades considering both the quantitative aspects involved (Water Resources bulletin 1992) and the necessity of ensuring an adequate water quality level (Water Resources Management Study Group Report, 1998). As regards the first issue, particular attention has been recently paid to the formalization of water resources distribution problems within a multi-objective framework (Water Resources bulletin 1992). Ghana utilizes water for hydro-power, both domestic and industrial purposes at urban and community levels, irrigation purposes for agriculture (crops, livestock and fisheries) etc.

Water resources in Ghana and indeed in sub-Sahara African have become a strategic commodity with supply limited in terms of quality and quantity, and demand for the commodity increasing due to population growth and economic development. Traditionally, water has been treated as though it were available in unlimited quantities and supplied at no cost or low cost to the consumer. The commodity has always been treated as a social good instead of an economic resource.

Water is no longer a free good. It is a finite resource with supply constraints. It has a scarcity value and there is a cost to using it. The energy crisis, of recent times (especially in 1997), within and outside the country, makes it imperative to improve the quality of

${ }^{2}$ Dr. Owusu-Ansah, E., Prof. Dontwi, I. K., \& Dr. Oduro-Yeboah, are all lecturers at the Department of Mathematics, Kwame Nkrumah University of Science \& Technology, Kumasi, Ghana; and Dr. AsieduAddo, S. K. is a lecturer at the Department of Mathematics Education, University of Education, Winneba, Ghana. 
Optimal Allocation of Flows (Water) Within the Volta Basin System of Ghana

Owusu-Ansah, E., Dontwi, I. K., Asiedu-Addo, S. K. \& Oduro-Yeboah, J

our decision making for flow allocation management. In the literature about water quality models, major emphasis has been put on modeling and analysis rather than on decisional issues. This is mainly due to the very complex nature of the physical models under consideration in which several sub-models interact at different time and space scales. Multi-object frameworks have been proposed to deal with decisional problems regarding water management issues (see for example O'laoghaire and Himmelblau, 1974). Efficient water resource management is crucial for economic development for the following reasons.

(1) To guide national policies and programs on further hydropower projects in terms of sitting and sizing of reservoirs and the type of turbines to use;

(2) To help set policy framework and guidelines for irrigation projects, agricultural policies and diversification in agriculture production;

(3) To set the stage for comprehensive planning and management of water resources in the Water Basins in Ghana.

(4) There will be an economic gain if an optimal flow allocation scheme is adopted to guide all hydropower and irrigation projects.

Linear programming methods have been used to plan the sizing of new reservoirs to meet projected power and irrigation demands (Bazaraa et. al., 1990). O'Laoghaire et al. (1974) used a combination of linear and dynamic programming to find the reservoir operating rules of a complex river system comprising the rivers, canals, and dams of Northern California that were part of the California water plan. This implies that the development and management of water resource in a river basin is not new in other parts of the world but this is not common in Africa and for that matter in Ghana. Nevertheless, we could replicate the ideas to manage and plan our water basins.

However, at the centre of planning and management of water resources is the problem of availability of water (flow) which is the basic input for any system we can develop for any river basin (Ford and Fulkerson, 1962). More so, the need to look at flow issues within the Volta Basin system and for that matter the sub-Sahara area has been accentuated by the recent weather variations and the population increase with its attendant increase in demand for water.

This paper presents a network and optimization modeling tools for managing and planning flow allocation and withdrawals. In this way, we use management mathematics tools in solving a basic and fundamental problem in Water resources planning and management.

\section{Model Calibration}

In designing the network for the Volta Basin System, we were guided by the spatial configuration of rivers and the geographical or relief features in the basin (Kenning and Helgason, 1980). The network we seek to develop has four source nodes indicating the runoffs in the Black Volta, White Volta, Lower Volta and Daka, and Oti sub-basins. The sub-basins are indicated by node 1 (Black Volta), node 2 (White Volta), node 3 (Lower Volta and Daka) and node 4 (Oti). For expediency, we employed the lumped parameter 
approach where most of the variables are lumped into some parameters. This approach has been employed due to inadequate information on flow in the basin.

The graph in Figure 1 shows the water transport network in the Volta Basin. The nodes from $1-4$ represent the flow input sources, nodes $5-10$ represent some gauging stations with up - to - date flows. These are, node 5 (Daboya), node 6 (Kulpawn), node 7 (Yarugu/Nangodi), node 8 (Bui), node 9 (Bamboe) and node 10 (Nawuni); node 12 (the Akosombo Dam).

The problem consists of finding a flow through the given graph that best satisfies the needs of the sink (nodes 12) taking into account the availabilities of flows at the subbasins (nodes 1-4). This problem is a classical maximum flow problem. Since maximum flow models require only one source node and one destination (sink) node (Mandl, 1979), we transform the graph by creating a fictitious node called SOURCE (node 11 in Figure 2) connected to the sub-basins by four arcs $(11,1),(11,2),(11,3)$ and $(11,4)$ with capacities corresponding to the mean annual runoffs from the four sub-basins $(7,778$, 9,506, 10,247 and 12,346 million cubic metres). The capacities of the various arcs are shown in Table 1.

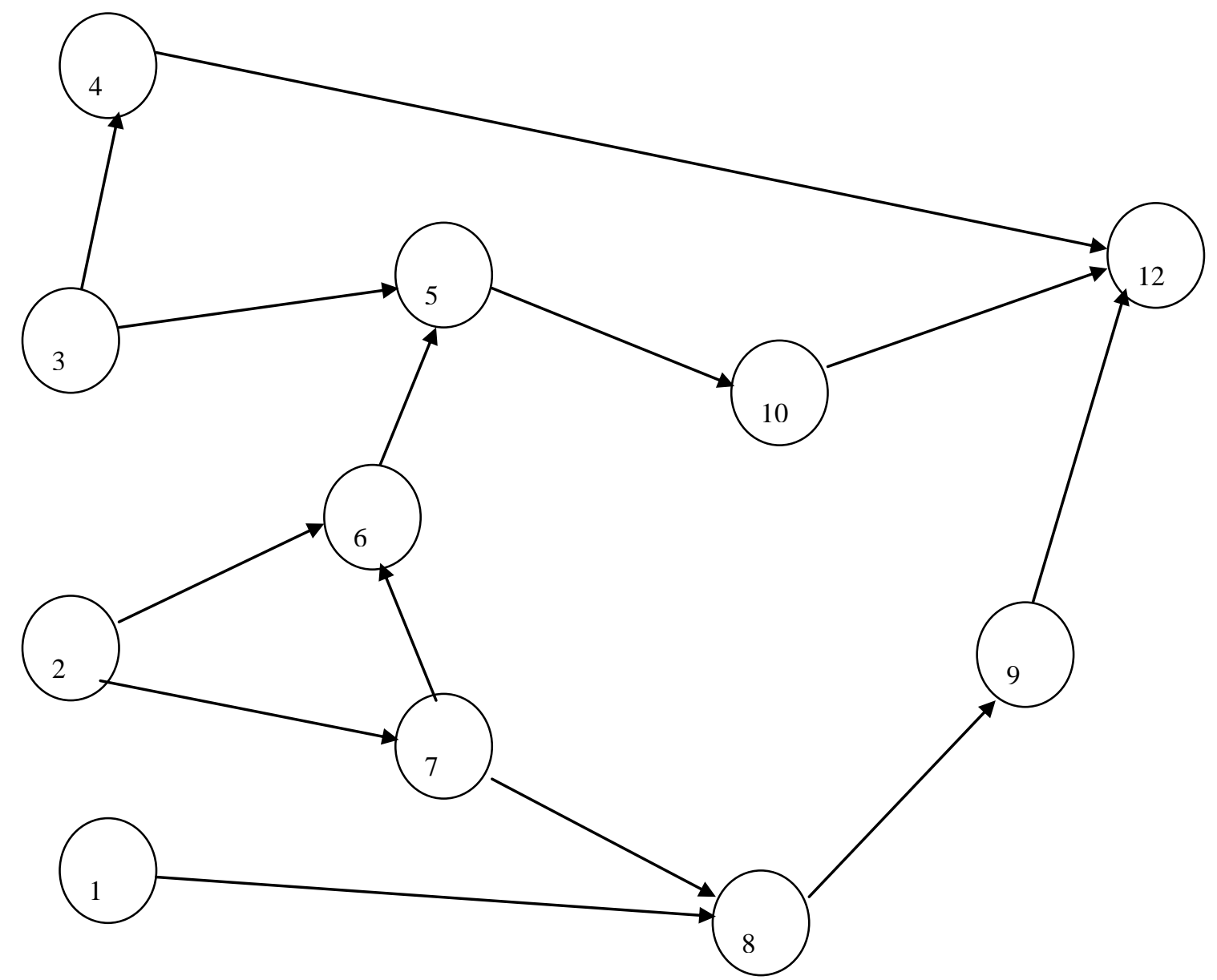

Figure 1Transportation network of the Volta Basin 
Optimal Allocation of Flows (Water) Within the Volta Basin System of Ghana

Owusu-Ansah, E., Dontwi, I. K., Asiedu-Addo, S. K. \& Oduro-Yeboah, J

In preparing a mathematical model that is compatible with the solution technique available for solving the flow allocation problem, we make the following assumptions:

(1) A source node and a destination node are linked through a network of finite capacity arcs.

(2) The network is unidirectional, that is, flow starts at the source node and leaves at the destination node

(3) Nodes act as transshipment points, collecting flows from entering branches and disbursing flows on leaving branches.

(4) Flow accounts for two facts of water resources:

(a) withdrawal consumptive (hydropower)

(b) withdrawal non-consumptive (irrigation).

The resulting graph (Figure 1) is a transport network

$G=(N O D E S, A R C S, C A P, S O U R C E$, SINK $)$ in which:

- NODES is the set of nodes;

- ARCS is the set of arcs;

- $C A P_{\mathrm{ij}}$ denotes the capacity of the arc $a=(i, j)$;

- SOURCE is the fictitious source (node 11);

- SINK is the sink (node 12).

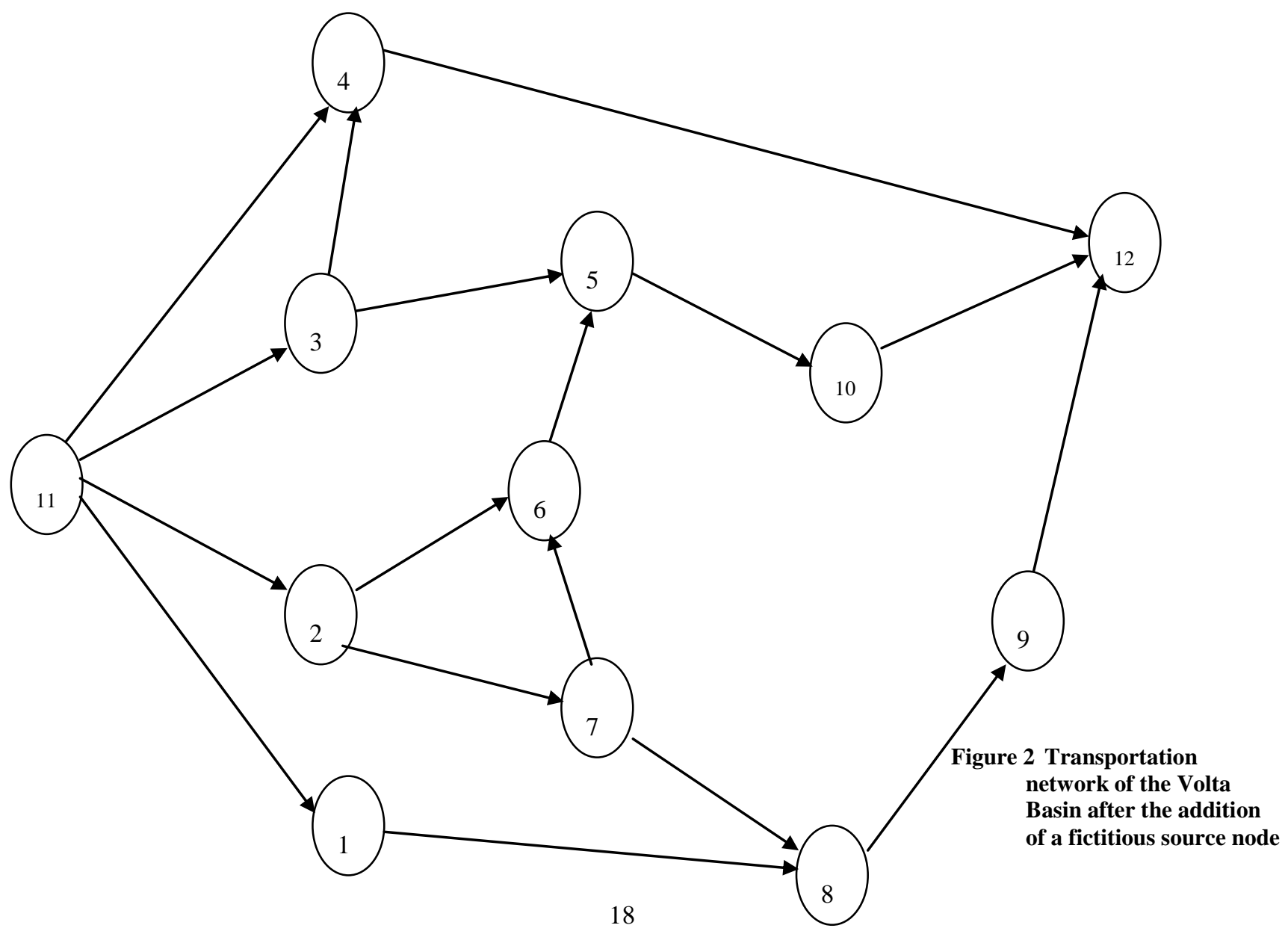


We denote the set of immediate successors of a node $\mathrm{i}$ by SUCCi and PREDi the set of its immediate predecessors.

Table 1 Initial Configuration for the Network Problem

\begin{tabular}{|c|c|c|c|}
\hline Arc & From Node & To Node & Capacity (Million Cubic Metres \\
\hline 1 & 1 & 8 & 7,161 \\
\hline \multicolumn{4}{|l|}{2} \\
\hline 3 & 2 & 7 & 3,457 \\
\hline \multicolumn{4}{|l|}{4} \\
\hline 5 & 2 & 6 & 5,556 \\
\hline \multicolumn{4}{|l|}{6} \\
\hline 7 & 3 & 5 & 1,235 \\
\hline \multicolumn{4}{|l|}{8} \\
\hline 9 & 3 & 4 & 8,776 \\
\hline 10 & 5 & 10 & \\
\hline 11 & 6 & 5 & 9,877 \\
\hline 12 & 7 & 6 & \\
\hline 13 & 7 & 8 & 8,642 \\
\hline 14 & 8 & 9 & \\
\hline 15 & 9 & 12 & 3,087 \\
\hline 16 & 10 & 12 & \\
\hline \multirow[t]{11}{*}{17} & 4 & 12 & 1,852 \\
\hline & 11 & 1 & \\
\hline & 11 & 2 & 9,877 \\
\hline & 11 & 3 & \\
\hline & 11 & 4 & 11,111 \\
\hline & & & 10,494 \\
\hline & & & 20,988 \\
\hline & & & 7,778 \\
\hline & & & 9,506 \\
\hline & & & 10,247 \\
\hline & & & 12,346 \\
\hline
\end{tabular}

If we let $x_{i, j}$ denote the flow on an arc $(i, j)$ and $Z_{0}$, the total flow in the transport network, then the problem that we need to solve corresponds to searching for the maximum flow between the nodes SOURCE and SINK, that is, a flow maximizing $Z_{0}$. 
Optimal Allocation of Flows (Water) Within the Volta Basin System of Ghana

Owusu-Ansah, E., Dontwi, I. K., Asiedu-Addo, S. K. \& Oduro-Yeboah, J

Table 2 Optimal Solution:

\begin{tabular}{|c|c|c|c|c|c|}
\hline Arc & $\begin{array}{l}\text { From } \\
\text { Node }\end{array}$ & $\begin{array}{c}\text { To } \\
\text { Node }\end{array}$ & $\begin{array}{c}\text { Capacity } \\
\text { (Million Cubic } \\
\text { Metres }\end{array}$ & $\begin{array}{c}\text { Flow Amount } \\
\text { (Million Cubic } \\
\text { Metres) }\end{array}$ & $\begin{array}{c}\text { Flow Balance } \\
\text { (Million Cubic } \\
\text { Metres ) }\end{array}$ \\
\hline 1 & 1 & 8 & 7,161 & 7,161 & $134 *$ \\
\hline \multicolumn{6}{|l|}{2} \\
\hline 3 & 2 & 7 & 3,457 & 3,457 & $1,481 * *$ \\
\hline \multicolumn{6}{|l|}{4} \\
\hline 5 & 2 & 6 & 5,556 & 5,556 & $1,481 * *$ \\
\hline \multicolumn{6}{|l|}{6} \\
\hline 7 & 3 & 5 & 1,235 & 1,235 & $1,481 * *$ \\
\hline \multicolumn{6}{|l|}{8} \\
\hline 9 & 3 & 4 & 8,776 & 8,642 & $1,481 * *$ \\
\hline 10 & 5 & 10 & & & \\
\hline 11 & 6 & 5 & 9,877 & 8,396 & $1,481 * *$ \\
\hline 12 & 7 & 6 & & & \\
\hline 13 & 7 & 8 & 8,642 & 7,161 & $1,481 * *$ \\
\hline 14 & 8 & 9 & & & \\
\hline 15 & 9 & 12 & 3,087 & 1,605 & $1,481 * *$ \\
\hline 16 & 10 & 12 & & & \\
\hline \multirow[t]{11}{*}{17} & 4 & 12 & 1,852 & 1,852 & - \\
\hline & 11 & 1 & & & \\
\hline & 11 & 2 & 9,877 & 9,013 & $617 *$ \\
\hline & 11 & 3 & & & \\
\hline & 11 & 4 & 11,111 & 9,013 & $493 *$ \\
\hline & & & 10,494 & 8,396 & $370 *$ \\
\hline & & & 20,988 & 20,988 & - \\
\hline & & & 7,778 & 7,161 & $617 *$ \\
\hline & & & 9,506 & 9,013 & $493^{*}$ \\
\hline & & & 10,247 & 9,877 & $370 *$ \\
\hline & & & 12,346 & 12,346 & - \\
\hline
\end{tabular}

*Flow for withdrawal consumptive purposes surplus

**Flow that can be redistributed for withdrawal non-consumptive purposes 
Hence the following mathematical programming model is adopted to solve the network problem.

$$
\begin{aligned}
& \max Z_{0} \\
& \text { subject to } \\
& \forall(i, j) \in A R C S: x_{i j} \leq C A P_{i j} \\
& \forall i \neq S O U R C E, \text { SINK : } \sum_{j \in S U C C_{I}} x_{i, j}=\sum_{j \in P R E D_{I}} x_{i, j} \\
& Z_{0}=\sum_{i \in P R E D_{\text {SINK }}} x_{i, S I N K} \\
& \forall(i, j) \in A R C S: x_{i j} \geq 0
\end{aligned}
$$

The constraints (1) indicate that the flow $x_{i, j}$ on every arc $(i, j)$ must not exceed the capacity CAPi,j of this arc. The constraint (2) specify that the total flow arriving at any node $\mathrm{i}$ also has to leave this node (with the exception of the source and sink nodes). The constraint (3) indicates that the total flow $\mathrm{Z}_{0}$ in the network equals the flow arriving at the sink (it is also equal to the flow leaving the source). Finally, the non-negativity constraints for the variables are given in (4).

It is possible to let non-integer flows pass through the arcs. However, in this type of problem, the simplex algorithm automatically finds integer solution values in the optimal solution to the linear problem if all capacities are integer (Philips and Gracia-Diaz, 1981). The optimal solution of the problem is shown in Table 2.

\section{Discussion}

Flows controlled or directed around the Mole and Laboni catchments areas through the South-Western part of the Upper - West region (through node 7 to node 8) could generate a flow between 370 million cubic metres and 1, 872 million cubic metres which could be redistributed along some flow paths within the White and Black Volta subbasins. This scheme is expected to transport into the Akosombo reservoir (described as the sink of the network) a flow of about 38,397 million cubic metres.

On water demand and supply within the Volta Basin system:

(1) A flow of about 370 million cubic metres can be made available for water needs in and around the Upper West Region as indicated by arcs $(11,1)$ and $(1,8)$

(2) There is a flow of about 1, 482 million cubic metres made available for redistribution in the White and Black Volta sub-basins for withdrawal nonconsumptive purposes.

(3) In the White Volta sub-basin, arc $(11,2)$ can make available a flow of 493 million cubic metres for withdrawal consumptive use. 
Optimal Allocation of Flows (Water) Within the Volta Basin System of Ghana

Owusu-Ansah, E., Dontwi, I. K., Asiedu-Addo, S. K. \& Oduro-Yeboah, J

(4) In the Lower Volta and Oti basins, a flow of 370 million cubic metres was allocated for consumptive use.

The arcs' (branches') capacities in the final configuration set the minimum amount of flow expected along each arc.

\section{Conclusion}

In this paper, an attempt has been made to design an allocation or distribution scheme that will help direct future constriction of canals to control and direct runoffs into minor and major reservoirs within the Volta Basin System to meet withdrawal consumptive and non-consumptive needs. It is hoped that this paper will set the stage and base for further work in:

i. planning irrigation water supply alternatives

ii. estimating average firm power of a reservoir

iii. sizing and sequencing of reservoir of must be stated that this design could be replicated in other basins in Ghana.

\section{References}

Bazaraa, M, J. Jarvis, and H. Sherall (1990), Linear Programming and Network Flow, $2^{\text {nd }}$ ed; Wiley, New York.

Ford, L; and D. Fulkerson (1962) Flows in Networks, Princeton University Press, Princeton N. J.

Kenning, J., and R. Helgason, (1980) Algorithms for Network Programming, Wileyinterscienze, New York.

Mandl, C., Allied (1979) Network Optimization, Academic Press, Orlando, Fla.

O'laoghaire, D. T., and D.M. Himmelblau (1974), Optimal Expansion of a water resource system, Academic Press, New York, pp 29 - 37.

Philips, D and A. Gracia-Diaz, (1981) Fundamentals of Network Analysis, Prentice Hall, Englewood Cliffs, N. J.

Water Resources Bulletin (1992)

Water Resources Management Study Group Report (1998), Ministry of Works and Housing, Vol.1, pp Al- G32. 